\title{
QUO VADIS AKSI 22 LASKAR PEMBELA ISLAM MENOLAK TEMPAT PROSTITUSI DI KABUPATEN PAMEKASAN DALAM BINGKAI SOCIAL MOVEMENT
}

\author{
Abu Muslim \\ abumuslimm04@gmail.com \\ Pascasarjana UIN Sunan Kalijaga Yogyakarta
}

\begin{abstract}
ABSTRAK
This paper aims to reveal how the Islamic Defenders Army, under the affiliation of FPI, carried out the 22 January action against the closure of the protest site in Pamekasan. This article originated from the issue of the LPI sweeping action in Langtolang Hamlet, Ponteh Village, Pamekasan which was charged as an illegal protest site in Pamekasan but resulted in violence and clashes. In the following incident, the Islamic Defenders Army group carried out 22 actions regarding the closure of the protest center in Pamekasan at the Regent's office. This marks a social, political, and symbolic event that is quite complex and interesting to discuss. Talking about symbolic events is ambiguous. In this incident, however, the people of Pamekasan knew that what was called the Defense Action 22 was an opportunistic response to protists in Pamekasan that violated local regulations and Islamic law. First, where this action is seen as a representation of Pamekasan Muslims as a Muslim identity, such as the implementation of Shari'ah law. Second, this event has provided the Laskar Pembela Islam (LPI) opportunity to erase the collective memory of the violence they have committed through political currents.
\end{abstract}

Tulisan ini bertujuan untuk mengungkap bagaiamana Laskar Pembela Islam di bawah afiliasi FPI dalam melakukan Aksi 22 Januari atas penutupan tempat protistusi di Pamekasan. Tulisan ini berawal dari persoalan aksi sweeping LPI di Dusun Langtolang, Desa Ponteh, Pamekasan yang diduga sebagai tempat protistusi ilegal di Pamekasan namun berujung pada tindakan kekerasan serta

Spiritualis, vol. 6, no. 2, September 2020

ISSN: 2442-5907|109 
Spiritualis: vol. 6, no. 2, September, 2020 |110

bentrokan. Pada peristiwa selanjutnya kelompok Laskar Pembela Islam melaukan aksi 22 tentang penutupan tempat protistusi di Pamekasan di kantor Bupati. Hal ini menandai peristiwa sosial, politis, dan simbolis yang cukup kompleks dan menarik untuk diperbincangkan. Berbicara tentang peritiwa simbolis memiliki dwimakna. Pertama, bagaimanapun peristiwa ini, masyarakat Pamekasan tahu bahwa apa yang disebut sebagai Aksi Bela 22 adalah sebagai respon oportunistik terhadap protistusi di Pamekasan yang melanggar Perda dan syariat Islam. Aksi ini dianggap sebagai representasi umat Islam Pamekasan sebagai identitas Muslim, seperti pelaksanaan hukum Syari'ah. Kedua, peritiwa tersebut telah memberikan peluang Laskar Pembela Islam (LPI) untuk menghapus memori kolektif mengenai kekerasan yang telah dilakukan mereka melalui arus politik.

Kata Kunci: Protistusi Pamekasan, Syariat Islam, LPI.

\section{A. Pendahuluan}

Kasus LPI (Laskar Pembela Islam) di bawah Front Pembela Islam (FPI) yang menyisir Dusun Langtolang, pada Jumat (19/1/2018) lalu yang diduga di desa itu terdapat sebuah rumah yang dijadikan tempat prostitusi ilegal menyisakan kekerasan yang tragis. Pada Penyisiran atau aksi sweeping yang dilakukan Laskar Pembela Islam (LPI) di bawah organisasi Front Pembela Islam (FPI) di Dusun Langtolang, Desa Ponteh, Pamekasan itu terjadi kekerasan dan bentrokan yang menyebabkan 5 orang warga terluka dan beberapa kendaraan bermotor milik kelompok LPI dirusak, yakni 1 unit mobil Suzuki Swift serta 1 unit sepeda motor Honda Beat. ${ }^{1}$

Berkenaan dengan kasus tersebut, pada hari senin pagi 22 Januari 2018 ribuan masyarakat bersama ulama Madura dan Para

\footnotetext{
${ }^{1}$ https://m.cnnindonesia.com/nasional/20180122065509-20-270593/sweepinglaskar-fpi-dan-perlawanan-balik-warga-pamekasan/diakses pada tanggal 19 Januari 2019.
} 
Tokoh Laskar Pembela Islam (LPI) menggelar aksi demo di Lapangan Pendopo Ronggo Sukowati Pamekasan, Madura, Jawa Timur. Mereka melakukan aksi demonstran tersebut karena ingin menagih janji Pemerintah Daerah setempat terkait penutupan tempat-tempat karaoke dan tempat prostitusi yang ada di Kabupaten Pamekasan. Laskar Pembela Islam Madura di depan ribuan umat dengan tegas menyatakan bahwa perjuangan menegakkan kebenaran tersebut akan terus dilanjutkan, maskipun informasi yang disampaikan kepada para tokoh ulama semua tempat hiburan sudah ditutup. Untuk memastikan tersebut, Tim Laskar Pembela Islam (LPI) mengkroscek kembali lokasi tempat hiburan di sana. ${ }^{2}$ Akibat peristiwa tersebut - sebagaimana janji Bupati Pamekasan setelah penangkapan pelaku sex komersil di desa Ponteh - dengan tegas Drs. Kholil Asyari menyatakan di depan masyarakat bahwa semua tempat hiburan di kabupaten Pamekasan akan ditutup.

Memang di Kabupaten Pamekasan terdapat suatu penerapan atau memberlakuan syariat Islam yang sudah dimulai sejak tahun 2002 melalui program Gerbang Salam. Tujuan diberlakukannya Gerbang Salam tersebut adalah untuk merealisasikan gagasan Pemerintah Kabupaten Pamekasan dalam mewujudkan ajaran Islam yang sempurna, tidak hanya pada tataran nilai, tataran teologis dogmatis, serta tataran aqidah saja, namun juga secara bertahap mampu diaktualisasikan pada tataran amaliyah yang diaplikasikan dalam kehidupan sehari-hari.

Kasus di atas dirasa sebagai represi sebuah kelompok yang dianggap liyan di tengah-tengah masyarakat di mana pendulum kekuasaan sudah tidak mutlak berada di tangan eksekutif (executive heavy). Dengan demikian, struktur kesempatan politik (political opportunity structure) menjadi terbuka lebar, sehingga turut memberikan andil yang besar dalam merangsang lahirnya gerakan

${ }^{2}$ http:/ / sorotpublik.com/berita-terkini/tagih-penutupan-tempat-karaokeribuan-massa-lpi-berdemo/diakses pada tanggal 19 Januari 2019. 
Spiritualis: vol. 6, no. 2, September, $2020 \mid 112$

sosial tersebut. Konsep political opportunity structure dinilai sangat relevan untuk membangun gerakan sosial karena dapat menjelaskan bahwa peluang politik yang terbuka akan mendorong kelompok-kelompok gerakan sosial untuk memanfaatkannya sebagai ruang untuk melakukan tekanan atau mendesakkan agenda-agenda gerakan agar dapat mencapai tujuan gerakan sosialnya.

Belakangan ini banyak disuguhkan sebuah realitas bahwa suatu organisasi keislaman seperti kehilangan genggaman dan kemampuan untuk mempengaruhi massa dalam hal inklusivisme. Barangkali, hal ini merupakan pernyataan yang berlebihan tetapi ini juga sangat mungkin terjadi dengan ditandainya "Aksi 22". Terkait dengan fenomena di atas. Penelitian ini hendak menggali gerakan sosial Islam lokal terhadap gerakan aksi demo Laskar Pembela Islam yang menolak tempat protistusi dalam membendung penerapan gerakan syariat Islam Pamekasan.

\section{B. Masyarakat Pamekasan dan Syariat Islam}

Keberagamaan masyarakat Pamekasan termasuk dalam kategori yang majemuk. Artinya di Kabupaten Pamekasan tidak hanya ada satu agama, namun ada beberapa agama resmi lainnya yang diakui oleh pemerintah. Kebanyakan penduduk yang tinggal di Kabupaten Pamekasan adalah suku Madura dan beberapa terdiri dari suku Jawa, masyarakat keturunan asing seperti, Arab, Cina, dan India. Agama yang dianut oleh para Penduduk Pamekasan, antara lain adalah Islam sebanyak 765.565 orang, Protestan 1.482 orang, Katolik 1.285 orang, Hindu 28 orang, Budha 322 orang, dan agama lain sebesar 49 orang.

Meskipun masyarakat Pamekasan mayoritas pemeluk agama Islam, tetapi agama selain Islam dapat leluasa untuk menunaikan ibadahnya dengan aman dan tenang. Hal ini menujukan keadaan yang positif terhadap kehidupan keagamaan karena mereka saling toleransi satu sama lain. Toleransi dalam agama ini menimbulkan kesadaran masyarakat Pamekasan yang 
Spiritualis: vol. 6, no. 2, September, $2020 \mid 113$

beragama Islam untuk senantiasa hidup berdampingan secara damai dengan warga non-muslim lainnya.

Kendati demikian, masyarakat Madura termasuk Kabupaten Pamekasan memiliki ciri khas dalam beragama. Sebagai penganut Islam, mereka dikenal sangat fanatik. ${ }^{3}$ Fanatisme tersebut, bisa dilihat bagaimana ketaatan masyarakat Madura dalam memeluk agama Islam. Selain itu, juga dapat dilihat dengan simbolsimbol yang identik dengan ciri atau tradisi yang ada dalam Islam. Di antara buktinya adalah jumlah masjid yang dibangun dengan megah, ketaatan, dan penghormatan yang sangat tinggi kepada sosok kiai. Disamping itu, keterkaitan Islam dengan orang Madura dapat dilihat dari bahasa Madura yang banyak mengadopsi dan sudah menyerap ratusan kosa kata bahasa Arab.

Citra mayoritas penduduk muslim di Pamekasan dapat ditemui beberapa pesantren besar yakni sekitar 100 lebih pesantren yang tersebar di 13 kecamatan yang memiliki pengaruh cukup luas di Kabupaten Pamekasan. Sebab, sudah menjadi budaya di Pamekasan, bahwa pesantren menjadi lembaga penting sehingga memiliki banyak basis dukungan dari massa yang fanatik. Selain itu, ketokohan kiai juga menjadi tolak diukur dari pesantren yang dimilikinya. Keberadaan beberapa pondok pesantren terkenal di Pamekasan dan jumlahnya yang cukup banyak memperkuat citra daerah ini kental sebagai daerah basis Islam.

Dengan kondisi sosial keberagamaan Islam seperti di atas, Kabupaten Pamekasan dalam upaya penegakan syariat Islam untuk mentransformasikan nilai-nilai ajaran Islam dalam kehidupan sehari-hari kemudian membentuk Gerakan Pembangunan Masyarakat Islami atau disebut juga Gerbang Salam.

Sejarah lahirnya Gerakan Pembangunan Masyarakat Islami di Pamekasan ini dilatar belakangi oleh asumsi-asumsi yang negatif dan tindakan-tindakan amoral seperti prostitusi, perjudian, pergaulan bebas dan maksiat lainnya yang kemudian mengundang

${ }^{3}$ Taufiqurrahman, Islam dan Budaya Madura (Bandung: Direktorat Pendidikan Tinggi Islam Departemen Agama RI, 2006), 2. 
Spiritualis: vol. 6, no. 2, September, 2020 |114

respon dari berbagai ormas-ormas serta elemen masyarakat Kabupaten Pamekasan. Upaya ini merupakan tahapan sekaligus bagian dari gerakan jangka panjang umat Islam Kabupaten Pamekasan dalam pemberlakuan syariat Islam melalui peningkatan pengamalan nilai-nilai ajaran Islam. ${ }^{4}$

Awalnya, Gerbang Salam merupakan manifestasi dari keresahan para ulama dan tokoh masyarakat setempat yang melihat gejala sosial khususnya pemuda pada tahun 2000 yang sudah mulai keluar dari ajaran agama. Kemudian gejala sosial tersebut menjadi bahasan dalam pertemuan rutin antara ulama dan umara' (pemerintah) yang digelar sebulan sekali. Bupati Pamekasan kala itu yakni Dwiatmo Hadiyanto memfasilitasi pertemuan rutin tersebut di pendopo Ronggo Sukowati. Munculnya gejala sosial pemuda yang menjurus pada dekadensi moral dan banyaknya aktifitas sosial yang menyimpang ditandai dengan maraknya kemaksiatan, seperti prostitusi, minum minuman keras, tawuran antar pelajar dan berbagai peristiwa lainnya.

Peristiwa tersebut mendorong forum ulama dan umara' ini mengambil langkah lebih jauh untuk memperbaiki kondisi Pamekasan agar lebih baik sekaligus membuat formula dan rumusan program. Seiring komitmen di atas, dalam upaya pelaksanaan syariat Islam di Pamekasan mulai berkembang dalam wacana dan pemikiran para tokoh agama, politisi, dan tokoh masyarakat. Masalah ini kemudian direspon oleh pemerintah Pamekasan dengan melaksanakan seminar penerapan syariat Islam. Kemudian upaya tersebut ditindaklanjuti melalui surat keputusan Bupati No. 188/126/441.012/2002 pada tanggal 30 April 2002 dengan pembentukan Lembaga Pengkajian dan Penerapan Syariat Islam (LP2SI). ${ }^{5}$

Gerakan ini meliputi tiga bidang, yakni bidang Aqidah, bidang syariat dan bidang akhlak. Dari ketiga aspek tersebut diharapkan dapat menghasilkan pribadi muslim yang kamil serta

${ }^{4}$ Tim LP2SI, Mengenal Gerbang Salam (Pamekasan: LP2SI, 2010), 3.

${ }^{5}$ Ibid., 2. 
shamil. Dengan beberapa misi membangun keluarga sakinah, membangun nuansa pendidikan yang Islami, aparatur pemerintah yang Islami, diharapkan mampu mewujudkan tatanan masyarakat yang Islami serta kesejahteraan dan ketentraman masyarakat. Diantara strategi yang digunakan adalah membangun motifasi kondusif bagi terciptanya perilaku dan sikap yang Islami serta membentuk kelompok pelopor sebagai penggerak pelaksanaan Gerbang Salam.

Selain ketiga program di atas terdapat beberapa program pokok, yaitu: dalam bidang pendidikan dengan membangun kebijakan yang mengarah pada pembangunan sistem pendidikan yang Islami. Kemudian dalam bidang sosial budaya dengan membuat kebijakan yang mengarah pada kerangka amar ma'rüf nabi munkar, seperti menutup aurat serta sholat berjamaah dan sebagainya. Selanjutnya, dalam bidang kesehatan dan keluarga diupayakan agar kebijakan yang diambil nantinya mengarah pada aturan yang sesuai dengan prinsip-prinsip Islam.

Dalam penerapan nilai-nilai syariat Islam, kelompokkelompok Islam yang mendukung terbentuknya LP2SI ini diantaranya adalah Al Irsyad cabang Pamekasan, Syarikat Islam, Persatuan Islam Pamekasan serta Nahdatulu Ulama dan Muhammadiyah, meski Nahdatulu Ulama dan Muhammadiyah dalam konteks nasional adalah dua kelompok orgaisasi Islam moderat ini tidak mendukung tetapi di Pamekasan kedua organisasi ini ikut mendukung penuh gerakan tersebut.

Masuknya Perda Syariah atau yang lebih diistilahkan dengan Gerbang Salam atau Gerakan Pembangunan Masyarakat Islami di kabupaten Pamekasan telah memberi arus politik baru dan nuansa baru baik ditingkatan elit politik maupun masyarakat biasa, tidak hanya didataran hukum, namun juga pada simbolsimbol yang berbau Islam pun tampil kepermukaan.

Dalam konteks Perda Syariah ini, kelompok atau golongan masyarakat dapat dibagi menjadi dua yaitu kelompok masyarakat yang pro (yang mendukung) dan masyarakat kontra (yang 
Spiritualis: vol. 6, no. 2, September, $2020 \mid 116$

menolak). Bagi kelompok yang pro, mereka berharap bahwa perda syariah ini dapat menjadi solusi berbagai masalah yang membelit bangsa dewasa ini. Harapan ini dipengaruhi oleh kegagalan negara yang mengintegrasikan program-program politik, budaya, dan ekonomi, dengan sistem nilai-nilai yang hidup dalam masyarakat dan juga kegagalan modernisasi dalam berbagai bidang yang dilakukan negara. Selain itu, menerapkan syariah lewat Perda dianggap sebagai perintah agama. Bagi masyarakat yang kontra, Perda syariah dinilai dapat mengganggu kerukunan antar umat beragama.

Aksi demo 22 di Lapangan Pendopo Ronggo Sukowati Pamekasan, adalah buntut dari kesepakatan rapat bersama antar tokoh masyarakat di atas. Mereka menuntut janji Pemerintah Daerah setempat terkait penutupan tempat-tempat karaoke dan tempat prostitusi yang ada di Kabupaten Pamekasan. ${ }^{6}$ Sebagaimana sebelumnya sempat terjadi penyisiran atau sweeping yang dilakukan oleh Laskar Pembela Islam (LPI). Organisasi ini di bawah naungan Front Pembela Islam (FPI) di Dusun Langtolang, Desa Ponteh, Pamekasan, Madura, yang berbuntut panjang. Sebab, pada saat penyisiran sempat terjadi kericuhan dan bentrokan dengan warga sehingga menyebabkan 5 orang warga terluka. Selain itu, beberapa kendaraan bermotor milik kelompok LPI dirusak, yaitu 1 unit mobil Suzuki Swift dan 1 unit sepeda motor Honda Beat. Tindakan main hakim sendiri oleh LPI-FPI ini, telah mengakibatkan trauma pada anak-anak dan kaum wanita.

Pada kesempatan yang sama, di depan ribuan umat dengan tegas PANGDA laskar Pembela Islam Madura, Kh. Abd Aziz Moh Syahid, menyatakan bahwa perjuangan menegakkan kebenaran tersebut akan terus dilakukan, maskipun informasi yang disampaikan kepada para tokoh ulama semua tempat hiburan sudah ditutup. Untuk memastikan semuanya sesuai dengan keinginan para tokoh ulama, Tim Laskar Pembela Islam yang

${ }^{6}$ http:// sorotpublik.com/berita-terkini/tagih-penutupan-tempat-karaokeribuan-massa-lpi-berdemo/diakses pada tanggal 19 Januari 2019. 
sudah dibagi tugas kembali mengkroscek lokasi tempat hiburan tersebut. $^{7}$

Setelah melakukan aksi demo, ribuan massa dari Front Pembela Islam (FPI) dan Laskar Pembela Islam (LPI) wilayah Madura, Jawa Timur, menggelar syukuran atas ditutupnya tempat prostitusi dan tempat karaoke di Kabupaten Pamekasan oleh Pemerintah Kabupaten (Pemkab), Selasa (22/1/2018). KH. Ali Karrar, Ketua Aliansi Ulama Madura (Auma) di hadapan massa mengucapkan terima kasih kepada pemerintah atas ditutupnya tempat terlarang itu karena telah menjadi penyakit masyarakat. Seperti praktek prostitusi yang terjadi di Desa Ponteh Kecamatan Larangan.

KH. Ali Karrar dalam orasinya menuntut Pemkab menutup secara permanen tempat karaoke dan prostitusi di Pamekasan, menutup rumah kos yang tidak sesuai dengan Peraturan Bupati Nomor 76 Tahun 2016 Tentang Penyelenggaraan Usaha Pemondokan, mencabut Perda Nomor 3 Tahun 2015 Tentang Hiburan dan Rekreasi karena Perda tersebut hanya menyuburkan praktek maksiat. ${ }^{8}$

\section{Gerbang Salam dan Aksi Bela Syariat Islam}

Aksi kolektif menentang atau mendesak dalam mewujudkan perubahan tentunya sama tuanya dengan perkembangan peradaban manusia itu. Perubahan satu peradaban masyarakat tidaklah selalu melalui jalan "damai". Bahkan sejarah membuktikan perubahan peradaban masyarakat kerap terjadi melalui aksi-kasi kolektif atau lebih dikenal dengan istilah gerakan sosial.

Atas dasar pemahaman tersebut,setidaknya dua macam tipe gerakan sosial, yakni gerakan sosial lama dan gerakan sosial baru. Gerakan yang lebih memfokuskan pada keresahan ekonomi bisa

\footnotetext{
7 Ibid., ${ }^{8}$ https://portalmadura.com/tempat-prostitusi-ditutup-fpi-lpi-pamekasan-gelarsyukuran-119940/ Diakses pada tanggal 19 Januari 2019.
} 
Spiritualis: vol. 6, no. 2, September, 2020 |118

disebut gerakan sosial lama. Biasanya gerakan sosial lama menyandarkan pada ideologi politik tertentu. Sedang gerakan sosial yang memfokuskan pada kaitan isu-isu simbolik dan kebudayaan dengan indentitas adalah gerakan sosial baru. Gerakan sosial baru biasanya menerima pluralisme ide serta cenderung mengembangkan pandangan pragmatis dalam upaya menciptakan sistem partisipasi politik seluas-luasnya dalam proses pengambilan keputusan. Gerakan sosial baru lebih menaruh perhatian pada life politics dibandingkan emancipatory politis seperti pada gerakan sosial lama. Oleh karenanya, keanggotaan gerakan sosial baru bersifat terbuka tanpa menghiraukan latar belakang kelas sosial, etnisitas, politik, maupun agama.

Kendati demikian, gerakan sosial tidak luput dari faktor grievance (keluhan) atau social discontent (perasaan tidak puas masyarakat). Faktor grievance ini menjadi penyebab yang mendorong munculnya gerakan sosial di dalam suatu masyarakat tertentu. Sebab grievance yang dialami masyarakat atau kelompok masyarakat yang sudah tidak mampu lagi dikelola dan dipikulnya maka melahirkan gerakan sosial. ${ }^{9}$

Selain faktor grievance terdapat juga suatu kesempatan yang mendorong lahirnya gerakan sosial, yakni struktur kesempatan politik (political opportunity structure) yang terbuka mempunyai andil dalam merangsang lahirnya gerakan sosial. Faktor political opportunity structure sangat relevan untuk membangun gerakan sosial, sebab dapat menjelaskan bagaimana peluang politik yang terbuka akan mendorong kelompok-kelompok gerakan sosial untuk memanfaatkannya sebagai ruang untuk melakukan tekanan atau desakkan pada agenda-agenda gerakan agar dapat mencapai tujuan gerakan sosialnya. ${ }^{10}$

\footnotetext{
'Sorensen, Aage B. "Toward a Sounder Basis for Class Analisys", American Journal of Sociology 105, 1523-1558 (Vermont: 2000), 34.

${ }^{10}$ Dela Porta, Donatella \& Mario Diani, Social Movements; An Introduction. (United Kingdom: Blackwell Publisher Inc. 1988), 9.
} 
Setelah melihat peluang politik, untuk menggerakan masa maka perlu menggunakan framing sebagai pembingkaian gerakan protes. Dalam framing ini dibutuhkan konsep mobilisasi struktur (mobilizing structure) yang dapat menjelaskan bahwa gerakan sosial itu membutuhkan organisasi, baik organisasi formal maupun tidak. Namun, organisasi gerakan tersebut haruslah memiliki struktur yang mudah untuk dimobilisir. Dalam konsep mobilizing structure ini menekankan pentingnya peranan aktor atau agent untuk memobilisasi struktur organisasi agar gerakan sosial tersebut mencapai hasilnya.

Istilah mobilisasi struktur dapat diartikan sebagai "kendaraan" untuk melakukan mobilisasi orang-orang lain untuk menjadi partisipan di dalam aksi kolektif. Mobilisasi struktur ini dapat dilakukan pada kelompok-kelompok lapisan bawah, organisasi-organisasi, dan jaringan informal guna membangun blok kolektif dari gerakan sosial dan revolusi. ${ }^{11}$

Dalam konteks ini,aksi demo 22 di Lapangan Pendopo Ronggo Sukowati Pamekasan, mereka menuntut janji pada Pemerintah Daerah setempat terkait penutupan tempat-tempat karaoke dan tempat prostitusi yang ada di Kabupaten Pamekasan. ${ }^{12}$ Upaya ini dilakukan dalam rangka mentransformasikan nilai-nilai Islam dalam kehidupan sehari-hari sebagaiamana dalam Gerbang Salam. Upaya ini merupakan tahapan sekaligus bagian tidak terpisahkan dari gerakan jangka panjang umat Islam Kabupaten Pamekasan dalam pemberlakuan syariat Islam melalui peningkatan pengamalan nilai-nilai ajaran Islam. ${ }^{13}$

Gerakan aksi 22 Islam lokal yang menentang masyarakat Dusun Langtolang, Desa Ponteh, Pamekasan berkaitan dengan

${ }^{11}$ McAdam Doug, Jhon D. McCarthy, Meyer N Zald. Comparative Perspectives On Social Movement: Political Opportunities, Mobilizing Sructures, and Cultural Framings. (United Kingdom: Cambridge University Press. 1999), 3.

12 http://sorotpublik.com/berita-terkini/tagih-penutupan-tempat-karaokeribuan-massa-lpi-berdemo/

${ }^{13}$ Tim LP2SI, Mengenal Gerbang Salam (Pamekasan: LP2SI, 2010), 3. 
Spiritualis: vol. 6, no. 2, September, 2020 |120

persoalan protistusi ilegal. Terutama berkaitan dengan kehormatan dan nilai-niai agama yang harus diikuti oleh masyarakat Pamekasan, sebagaimana pembahasan di atas mayoritas agama penduduk Pamekasan adalah Islam yanng sudah meresap dan mewarnai kehidupan sosial mereka.

Aksi sweeping oleh FPI dan LPI yang kemudian berujung penyerangan dan bentrokan di Dusun Langtolang, pada Jumat (19/1/2018) berlatar belakang atas dugaan bahwa di desa itu terdapat sebuah rumah yang dijadikan tempat prostitusi ilegal. Aksi tersebut menyisakan kekerasan yang tragis. Faktor-faktor tersebut merupakan keluhan (grievance) Laskar Pembela Islam terhadap keberadaan protistusi ilegal yang dianggap menyimpang dari nilainilai keislaman.

GerakanLaskar Pembela Islam membingkai otoritas dirinya sebagai kelompok yang memegang teguh prinsip Islam yang benar, dan menyerang lawannya sebagai kelompok lain yang menurut mereka tidak Islami, sebab protistusi adalah tindakan degradasi moral. Dalam kasus di Pamekasan ini, struktur kesempatan politik bisa terwujud karena terdapat dukungan pemerintah dalam kebijakan yang diambil, di mana lebih cenderung memprioritaskan kelompok Islam sebagaimana aspirasi kelompok aksi demo 22. Pesan menyebar luas kepada massa Muslim Pamkeasan, bahwa gerakan aksi demo tersebut mendapatkan momentum yang baik secara politik, karena massa Islam merasa bahwa pemerintah dalam hal ini aparat keamanan, memberikan ruang untuk terjadinya struktur politik yang mendorong aksi demo terhadap protistusi di Pamekasan. Selain itu, Perda yang berbasis syariat Islam juga menjadi legetimasi aksi demo tersebut. Sebagaimana uraian di atas, dalam kasus aksi demo di Pamekasan ini, yang terjadi adalah struktur dukungan politik sekaligus struktur kesempatan politik.

Mobilisasi yang ditunjukkan melalui serangkaian aksi yang disebut Aksi 22 menolak tempat protistusi pada awalnya dimotori oleh Front Pembela Islam (FPI) dan Laskar Pembela Islam Pamekasan. Aksi ini dalam analisis sosiologis sebenarnya 
Spiritualis: vol. 6, no. 2, September, 2020 |121

merupakan suatu bentuk demonstrasi massa. Di mana aksi ini ditujukan untuk melakukan tekanan secara paksa untuk kepentingan politik khususnya dan juga kepentingan jangka pendek untuk suatu perubahan. Tekanan untuk perubahan politik dengan menggunakan aksi massa dapat diupayakan seperti demonstrasi secara besar-besaran dengan cara memaksakan kehendak. Pemaksaan ini bisa menggunakan kekerasan, baik secara fisik maupun secara simbolik, yang sering disebut dengan istilah 'mobocracy' atau diperintah atau didominasi dengan kekuatan massa.

Pada konteks sosio-religius, hal tersebut dinilai sebagai gerakan protes murni. Konteks ini tujuan yang disuarakan oleh masyarakat Islam Pamekasan pada dasarnya merupakan sebuah kepedulian terhadap upaya pemurnian agama, atau lebih tepatnya pemurnian ajaran agama Islam yang sesuai dengan nilai-nilai keislaman. Dengan demikian kegiatan muaammalah yang tidak sesuai dengan Perda dan praktek Islam akan dianggap bersalah. Tujuan implisit gerakan aksi demo 22 Pamekasan dalam konteks sosio-kultural adalah untuk membubarkan praktek protistusi yang dinilai akan menggerus nilai-nilai keislaman di Kabupaten Pameksan. Selain itu, praktik prostitusi ini juga bertentangan dengan Perda sebagai manifestasi nilai-nilai keislaman.

Dari aksi demo 22 di Pamekasan setidaknya berdampak pada kedua kelompok. Bagi kelompok yangmelakukan demo aksi 22, mereka merasa bahwa hasil yang diperoleh jauh lebih besar dan berharga karena telah sukses melakukan penegakan syariat Islam sebagaimana Perda atau Gerbang Salam. Kemenangan tersebut sekaligus menujukan identitas mereka sebagai organisasi yang menegakan syariat Islam. Sementara itu, dampak yang dialami oleh orang-orang yang terlibat protistusi akibat gerakan aksi tersebut, bersifat kompleks dan multi dimensional; baik ekonomi, sosial, politik, keagamaan, psikologis, pendidikan, maupun dampak secara hukum.

Dalam menilai kejatuhan politik dari "Aksi 22 Pembubaran Tempat protistusi" sekali lagi amatlah penting untuk mengacu pada 
Spiritualis: vol. 6, no. 2, September, $2020 \mid 122$

analisa dari Judith Herman tentang analisa sosial dan konsekuensi psikologis pada kekerasan fisik dan psikis. Dia menyatakan bahwa: "Untuk dapat lolos dari tanggung jawab atas kejahatannya, para pelaku kejahatan melakukan segala hal dalam kuasanya yang dapat mendorong kelupaan".

Ketika para aktor dan aksi kekerasan memperoleh kekuasaan, mereka mempunyai empat pilihan terkait kekerasan dan memori kolektif: Pertama, melembagakannya; kedua, mengabaikannya dengan cara-cara yang mengarah pada amnesia kolektif; ketiga, mengubahnya menjadi kepahlawanan,dan keempat, mengalihkan fokus kepada musuh yang baru. Pada aksi tersebut LPI dan FPI telah terbukti menguasai strategi ketiga dan keempat.

Aksi 22 Januari 2018 lalu telah dikelola secara luar biasa untuk memastikan ekspos maksimal pada media sosial dan konvensional. Pencitraan LPI dan FPI sebagai "Pahlawan pembela Syariat Islam", telah berhasil menggeser citranya. Dalam hal ini dapat dipastikan bahwa mereka memiliki langkah efektif dalam menghapus memori kolektif tentang tindakan kekerasan yang dilakukan LPI. Setidaknya, hal tersebut telah menutupi wajah LPI. Tetapi kekerasan LPI tidak akan dilupakan oleh korban kekerasan, meskipun ingatan mereka disepelekan secara sosial dan emosional.

\section{Kesimpulan}

Aksi 22 dalam pengertian pengerahan massa dan demonstrasi yang dimobilisasi oleh LPI merupakan bagiand ari kontestasi politik. Sebab peristiwa tersebut dijadikan sebagai respon oportunistik terhadap protistusi di Pamekasan yang melanggar Perda dan syariat Islam. Pertama, aksi ini dianggap sebagai representasi umat Islam Pamekasan untuk menunjukkan identitas muslim mereka dengan cara menegakkan Perda hukum Syari'ah. Kedua, peritiwa tersebut telah memberikan peluang Laskar Pembela Islam (LPI) untuk menghapus memori kolektif mengenai kekerasan yang telah dilakukan mereka kepada masyarakat Dusun Langtolang, Desa Ponteh, Pamekasan melalui arus politik. 
Spiritualis: vol. 6, no. 2, September, 2020 |123

\section{DAFTAR PUSTAKA}

Aage B, Sorensen. "Toward a Sounder Basis for Class Analisys", American Joumal of Sociology 105, 1523-1558, Vermont: 2000.

Dela Porta, Donatella \& Mario Diani, Social Movements; An Introduction, United Kingdom: Blackwell Publisher Inc. 1988.

McAdam Doug, Jhon D. McCarthy, Meyer N Zald. Comparative Perspectives On Social Movement: Political Opportunities, Mobilizing Sructures, and Cultural Framings, United Kingdom: Cambridge University Press. 1999.

Taufiqurrahman, Islam dan Budaya Madura. Bandung: Direktorat Pendidikan Tinggi Islam Departemen Agama RI, 2006.

Tim LP2SI, Mengenal Gerbang Salam. Pamekasan: LP2SI, 2010.

https://m.cnnindonesia.com/nasional/20180122065509-20-

270593/sweeping-laskar-fpi-dan-perlawanan-balik-wargapamekasan/diakses pada tanggal 19 Januari 2019.

http://sorotpublik.com/berita-terkini/tagih-penutupan-tempat-

karaoke-ribuan-massa-lpi-berdemo/diakses pada tanggal 19 Januari 2019.

https://portalmadura.com/tempat-prostitusi-ditutup-fpi-lpipamekasan-gelar-syukuran-119940/ Diakses pada tanggal 19 Januari 2019. 